\section{Commentary: Multidisciplinary teamwork and precision medicine for thoracic aortic disease save lives}

\author{
Marion A. Hofmann Bowman, MD, and \\ Kim A. Eagle, MD
}

Aortic dissection remains among the most morbid and mortal conditions and occurs often in a dramatic fashion, with ripping chest pain, syncope, or sudden death and takes patients by great surprise in an untimeliest manner. What if we could prevent aortic dissection? What if we could identify patients at greater risk for aortic dissection and truly practice preventive medicine?

In this issue of the Journal, Drs Mary Roman and Julie De Backer ${ }^{1}$ provide a contemporary review on aortic aneurysm due to heritable aortopathy and make a compelling case to initiate screening of all first-degree relatives. Dissection of the thoracic aorta often occurs in patients with genetic variants in genes predisposing to aortic disease, such as genes encoding for vascular smooth muscle, extracellular matrix, or signaling pathways. Rarely, as in the case of Marfan syndrome or Loeys-Dietz syndrome, do the carriers of such variants show any syndromic findings, hence aortic dissection can be the first manifestation of the disease. Indeed, wholegenome sequencing on unselected patients with thoracic aortic dissection revealed in approximately $10 \%$ of cases the presence of a pathogenic variant. ${ }^{2}$ This study and others confirms the seminal findings by Biddinger and colleagues ${ }^{3} 25$ years ago, that up to $20 \%$ of individuals with thoracic aortic aneurysms and dissection who do not have a known syndrome (eg, Marfan syndrome, vascular Ehlers-Danlos syndrome, Loeys-Dietz syndrome) have a family history of thoracic aortic disease. Indeed, a recent population-based study in Denmark $^{4}$ confirmed that first-degree relatives of individuals

From the Division of Cardiology, Department of Internal Medicine, University of Michigan, Michigan Medicine, Ann Arbor, Mich.

Disclosures: The authors reported no conflicts of interest.

The Journal policy requires editors and reviewers to disclose conflicts of interest and to decline handling or reviewing manuscripts for which they may have a conflict of interest. The editors and reviewers of this article have no conflicts of interest.

Received for publication June 18, 2021; revisions received June 18, 2021; accepted for publication June 21, 2021; available ahead of print June 25, 2021.

Address for reprints: Marion A. Hofmann Bowman, MD, Division of Cardiology, Department of Internal Medicine, University of Michigan, 1150 W. Medical Center Dr, SPC 0644, Ann Arbor, MI 48109-5632 (E-mail: mhofmann@med.umich.edu). J Thorac Cardiovasc Surg 2022;163:46-7

$0022-5223 / \$ 36.00$

Copyright (C) 2021 by The American Association for Thoracic Surgery

https://doi.org/10.1016/j.jtcvs.2021.06.032

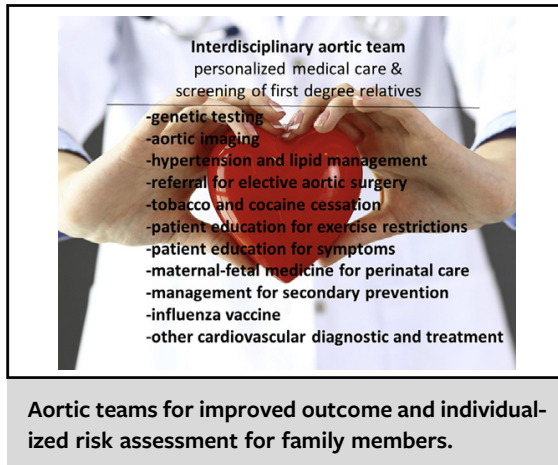

CENTRAL MESSAGE

Thoracic aortic dissection often occurs in the context of an inherited aortopathy, and this provides a unique opportunity for personalized medicine and risk stratification of their family members.

with aortic aneurysms and dissections had a hazard ratio of 6.7 for aneurysm and 9.2 for dissection over an average 7-year follow-up compared with matched controls. The risk was particularly high if a sibling or parent younger than the age of 50 years was affected by aortic disease.

Surgical treatment for aortic dissection has improved substantially, leading to a significant reduction in mortality and morbidity over the last decade. ${ }^{5,6}$ However, the surgeon can have an even larger impact on the health of his or her patients and their families by referring patients with aortic dissections to an "aortic clinic," a multidisciplinary team of experts in vascular medicine, cardiology, and genetic counselors with the recommendation to initiate genetic testing if appropriate. ${ }^{7}$

The review by Roman and De Backer in this issue of the Journal $^{1}$ provides a step-by-step tutorial on risk assessment, including appropriateness for genetic testing. By identifying other family members who could be at increased risk for aortic dissections, patients have the chance to lower their risk by a variety of measures with strict treatment of hypertension, surveillance aortic imaging, lifestyle changes aimed at reducing vascular risk factors as the cornerstones of personalized care, and timely referral for elective surgical repair of aneurysms. Recent data by our group showed a $30 \%$ increase in frequency of aortic type A dissection during the months with high community influenza prevalence, raising the question of whether influenza infection could be 


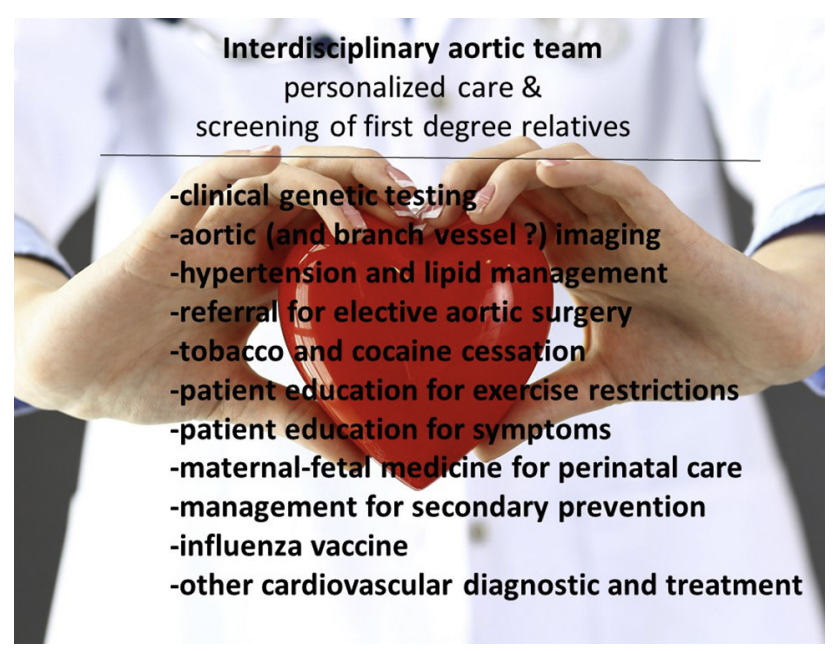

FIGURE 1. Multidisciplinary collaboration and specialized care in an "aortic center" are important to improve outcome and individualized risk assessment for family members of patients with aortic dissections. With the advance of genetic testing and international registries, we are in an area of personalized medicine to save lives.

a modifiable risk factor for aortic dissection. ${ }^{8}$ Until we have further data, we would like to propose that the annual flu vaccine should become part of the toolbox used in the care for patients with aortic disease. In summary, after recovery from aortic dissection, which is in large part due to timely and skillful surgery, patients benefit from an interdisciplinary and multispecialty care in an aortic center that addresses the many aspects of cardiovascular health (Figure 1).

\section{References}

1. Roman MJ, De Backer J. Hereditary thoracic aortic disease: how to save lives. $J$ Thorac Cardiovasc Surg. 2022;163:39-45.

2. Wolford BN, Hornsby WE, Guo D, Zhou W, Lin M, Farhat L, et al. Clinical im plications of identifying pathogenic variants in individuals with thoracic aortic dissection. Circ Genom Pres Med. 2019;12:e002476.

3. Biddinger A, Rocklin M, Coselli J, Milewicz DM. Familial thoracic aortic dilatations and dissections: a case control study. J Vasc Surg. 1997;25:506-11.

4. Raunso J, Song RJ, Vasan RS, Bourdillon MT, Norager B, Torp-Pederson C, et al. Familial clustering of aortic size, aneurysms and dissections in the community. Circulation. 2020;142:920-8.

5. Yang B, Rosati CM, Norton EL, Kim KM, Khaja MS, Dasika N, et al. Endovascular fenestration/stenting first followed by delayed open aortic repair for acute type A aortic dissection with malperfusion syndrome. Circulation. 2018;138:2091-103.

6. Evangelista A, Isselbacher EM, Bossone E, Gleason TG, DiEusani M, Sechtem U, et al. Insights from the International Registry of Acute Aortic Dissections. Circulation. 2018;137:1846-60.

7. Musunuru K, Hershberger RE, Day SM, Klinedinst NJ, Landstrom AP, Parikh VN, et al. Genetic testing for inherited cardiovascular diseases - a scientific statement from the American Heart Association. Circ Genom Precis Med. 2020;13:e000067.

8. Ashur C, Norton E, Farhat L, Conlon A, Willer C, Froehlich JB, et al. Higher admission rates and in hospital mortality for acute type A aortic dissection during Influenza season. Sci Rep. 2020;10:4723.

\section{Commentary: Thoracic aortic disease: One step closer to precision medicine}

\section{Teng C. Lee, MD, and Tom C. Nguyen, MD}

Despite recent advances in management, aortic dissection and rupture continue to be life-threatening conditions. More than $60 \%$ of individuals are not diagnosed before

\footnotetext{
From the Division of Adult Cardiothoracic Surgery, Department of Surgery, University of California San Francisco, San Francisco, Calif.

Disclosures: The authors reported no conflicts of interest.

The Journal policy requires editors and reviewers to disclose conflicts of interest and to decline handling or reviewing manuscripts for which they may have a conflict of interest. The editors and reviewers of this article have no conflicts of interest.

Received for publication March 21, 2021; revisions received March 21, 2021; accepted for publication March 23, 2021; available ahead of print March 26, 2021.

Address for reprints: Teng C. Lee, MD, Division of Adult Cardiothoracic Surgery, Department of Surgery, University of California San Francisco, San Francisco,

CA (E-mail: teng.lee@ucsf.edu).

J Thorac Cardiovasc Surg 2022;163:47-9

$0022-5223 / \$ 36.00$

Copyright (C) 2021 by The American Association for Thoracic Surgery

https://doi.org/10.1016/j.jtcvs.2021.03.072
}

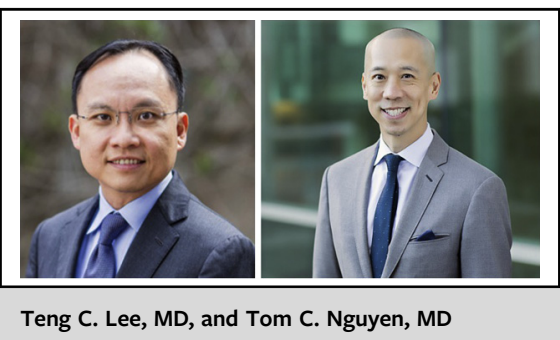

CENTRAL MESSAGE

Screening family members with thoracic aortic disease may allow the detection of otherwise asymptomatic disease and the planning of appropriate prophylactic surgery based on size and specific pathogenic genetic variants. 